National Aeronautics and Space Administration

Goddard Space Flight Center

Contract No.NAS $-5-3760$

$$
S T-A I-P F-10385
$$

\title{
EFFECT OF NEGATIVE IONS ON THE DIFFUSION OF CHARGED \\ PARTICLES IN THE LOWER IONOS PHERE
}

\author{
by \\ E. I. Ginsburg \\ [USSR]
}

GPO PRICE

$\$$

CFSTI PRICE(S)

Hard copy $(\mathrm{HC}) \angle$ CO
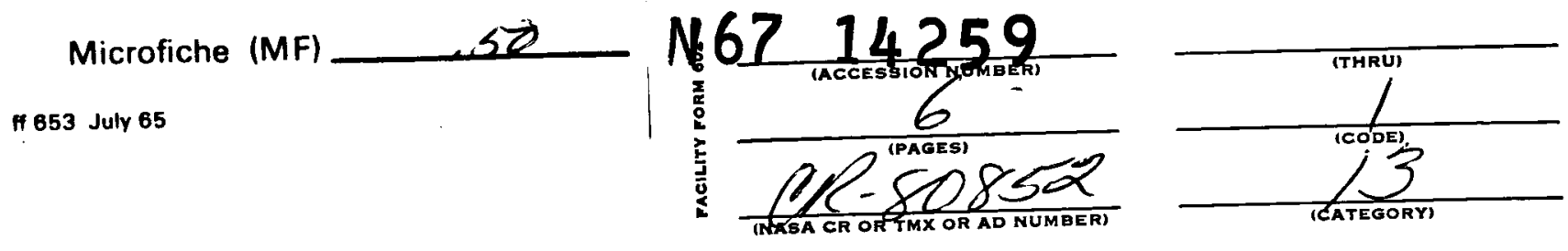

13 SEPTEMBER 1965 


$$
S T-A I-P F-10385
$$

EFFECT OF NEGATIVE IONS ON THE DIFFUSION OF CHARGED

PARTICIES IN THE LOWER IONOSPHERE *

TVUZ., Radiofizika

Tom 8, No. 3, 626-7,

by E. I. Ginzburg

Izd. Gor'kovskogo Universteta,

Gor'kiy, 1965

\section{SUMMAR Y}

The solution of this problem is arrived at by a method analogous to that expounded in [3] and is based upon the fact that the diffusion process in a plasma in the presence of a magnetic field takes place at the rate of the velocity of slower particles (electrons and positive ions), inasmuch as the electric field, emerging on account of the difference in the diffusion rates of electrons and ions, hampers a further separation of these particles and this is evidence that the presence of negative ions may substantially modify the character of the diffusion process.

In the conditions of the lower ionosphere the influence of negative ions is significant to heights of the order of $80 \mathrm{~km}$ [1]. However, in the works $[2,3]$ on the diffusion in the ionosphere the influence of negative ions on the diffusion process was not taken into account. The method, applied below, is analogous to that proposed in [3]: In the case, when the concentration of particles varies little over the length of the free path and when for the description of these particles' motion auring the free path time, macroscopic equations can be applied (in our case it concerns electrons, negative and positive ions). The 1inearized system of these equations is resolved alongside with the equation for the longitudinal electric field by way of expansion of the functions searched for into the Fourier integral by the coordinates $0 n_{k}=\int \delta n(r) e^{-i k r} d^{3} r$.

* VLIYANTYE OTRITSATEL'NYKH IONOV NA DIFFUZIYU ZARYAZHENIYKH OHASTITS V NIZHNEY IONOSFERE. 
At the same time we obtain for the Fourier-components of the functions ink the equations

$$
\begin{aligned}
& \partial \delta n_{e k} / \partial t+a_{H e}\left[D_{e} k^{2} \delta n_{e k}+4 \pi \sigma_{e}\left(\delta n_{e k}+8 n_{j k}-\delta n_{l k}\right)\right]=0 \\
& \partial \delta n_{l k} / \partial t+a_{H l}\left[D_{i} k^{2} \delta n_{l k}+4 \pi \delta_{l}\left(\delta n_{l k}-\delta n_{e k}-\delta n_{j k}\right)\right]=0 ; \\
& \partial \delta n_{j k} \partial t+\alpha_{H I}\left[D_{j} k^{2} \delta n_{j k}+4 \pi \delta_{j}\left(\delta n_{j k}+\delta n_{e k}-\delta n_{l k}\right)\right]=0 .
\end{aligned}
$$

Here $D_{e}=x T_{e} / m v_{e m}$ is the coefficient of longitudinal diffusion, $0_{e}=e^{2} n_{0 e} / m v_{e m}$ is the conductivity, $\omega_{H e}=e H_{0} / m c$ is the gyrofrequency for electrons, $a_{H e}=\left[1+\left(\omega_{H e} / v_{e m}\right)^{2} \cos ^{2} \theta\right]\left[1+\left(\omega_{H e} / v_{e m}\right)^{2}\right]^{-1}, \beta$ is the angle between $\mathbf{k}$ and $H_{0}, D_{l}, D_{j}, \sigma_{l}, \sigma_{j}, \omega_{H l}, \omega_{H l}$, $a_{H l}$ are the corresnonding quantities for the ions, $\delta n_{e}, \delta n_{i}, \delta n_{j}$ is the residual concentration respectively for the electrons, positive and negative ions, $n_{o e}, n_{o l}, n_{o j}$ is the mean concentration of these particles (i, $\left.n \ll n_{o}, n_{o f}+n_{o j}=n_{o l}\right), m, M_{l}, M_{i}$ are the masses of electrons and ions, $e$ is the charge of the electrons, $T_{e}, T_{i}$ are the temperatures respectively of electrons and ions, $x$ is the Boltzmann constant, vem. v/m: v/m are the frequencies of electrons' and ions' collisions with neutral particles, $E$ is the electric field strength, $H_{0}$ is the constant Earth's magnetic field. We shall write the solution of the system (I) in the form

$$
\begin{aligned}
& \delta n_{e k}(t)=\delta n_{e k}^{(1)} e^{-q_{1} t}+\delta n_{e k}^{(2)} e^{-q_{2} t}+\delta n_{e k}^{(3)} e^{-q_{j} t} \\
& \delta n_{i k}(t)=\delta n_{i k}^{(1)} e^{-q_{1} t}+\delta n_{l k}^{(2)} e^{-q_{2} t}+\delta n_{l k}^{3} e^{-q_{s} t} \\
& \delta n_{j k}(t)=\delta n_{j k}^{(1)} e^{-q_{1} t}+\delta n_{j k}^{(2)} e^{-q_{2} t}+\delta n_{j k}^{3} e^{-q_{s} t}
\end{aligned}
$$

where $q_{1}, q_{1}, q_{3}$ are the radicals of the characteristic equation.

We shall limit ourselves to the case, when the masses and the collision frequencies for various kinds of ions are identical (for the lower ionosphere it is realized in the presence of molecular oxygen ions only). At the same time, $M_{l}=M_{j}=M_{v} v_{l m}=v_{j m}$ and

$$
q_{0}=a_{H l} D_{t} k^{2}, \quad i_{n}^{(3)}=0 \text {. }
$$

If the characteristic dimensions of the perturbed region are large by comparison $w$ th the Debye $r$ dius $R_{D}$,

$$
\left(k R_{D}\right)^{2}=k^{2} \times T_{l} T_{e} / 4 \pi e^{2} n_{0}\left(T_{e}+T_{l}\right) \ll 1,
$$


then we shall have for the remaining quantitios in (2)

$$
q_{1}=4 \pi J_{e} a_{e}+4 \pi J_{u} a_{H i} \text {. }
$$

where

$$
\begin{aligned}
& \sigma_{u}=\tau_{l}+\sigma_{\jmath}=e^{2}\left(n_{o l}+n_{o j}\right) / M v_{l m}, \\
& q_{2}=k^{2} \frac{\left(\sigma_{u} D_{e}+\sigma_{e} D_{l}\right) a_{H e}{ }^{a} H l}{\sigma_{u}{ }^{\alpha}{ }_{H l}+\sigma_{e}^{\alpha} H e} \text {. }
\end{aligned}
$$

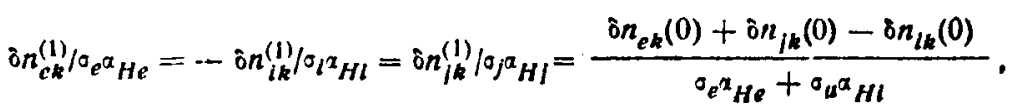

$$
\begin{aligned}
& \hat{o} n_{i k}^{(2)} / n_{o i}=-\hat{o} n_{j k}^{(2)} / n_{O J}=\delta n_{e k}^{(2)} /\left(n_{o i}+n_{o J}\right) \text {. } \\
& \hat{i} n_{i k}^{(3)}=\delta n_{j k}^{(3)}=\left\{n_{o l} \hat{o} n_{j k}(0)+n_{o j} \hat{o} n_{l k}(0)\right\} /\left(n_{o l}+n_{o j}\right) \text {. }
\end{aligned}
$$

Here $i n_{k e}(0)$, $i n_{i k}(0)$, $\delta n_{l k}(0)$ are the Fourier components of the initial disturbance of the density of electrons and ions.

One of the characteristic radicals ( $q_{1}$ in our case) describes the spreading out of the initial charge in the plasma, as should have been expected [3]. Inasmuch as $q_{1}$ is significantly greater than $q_{2}$ anc $q_{3}$, the process of diffusion takes place mairly at compensated plasma charge (ambipolar diffusion). At the same time $\delta n_{e k}^{(2)}=\delta_{n}{ }^{(2)}$. The electrons and the noncompensated ion charge, equal to $e\left(\hat{o} n_{i k}^{(2)}-i n_{j k}^{(2)}\right)=e \hat{o} n_{e k}(0)$, take part in the ambipolar diffusion process dercribed by the radical 92 . The compensated ion charee spreads out with the ion diffusion rate described by the radical $q_{3}$. In the first apnroximation by $k R_{D}$ the electrons do not take part in this process. The coefficient of ambipolar diffusion is

where $\lambda=\left(n_{o l}+n_{o j}\right) / n_{o e}$.

$$
D(\hat{\beta})=x\left(\lambda T_{e}+T_{i}\right)\left(\lambda m v_{e m} / \alpha_{H e}+M v_{l m} / \alpha_{H l}\right)^{-1} .
$$

iote tiat for tre lover ionosphere $\lambda$ may be significantly greater than the unity. That is why the anisotropy of the diffusion process may be manifest at very small heichts in the ionosphere. At heights where

$$
\left(\omega_{\mathrm{He}} \mathrm{l}^{\mathrm{vem}}\right)^{2} \ll 1 \text {. }
$$

the character of the diffusion is isotropic regardless of the form of the inhomogeneity. The dependence of inhomogeneity 's spreading our process on its initial structure was discussed at length in the work [3]. Here we shall note only that if it is not too strongly stretched out along the magnetic field (see [3]), the diffusion isotropy may take place to heights, 
where the condition (9) is disrupted. To that effect it is sufficient that we have $\left(\omega_{\left.H i i_{i m}\right)^{2} \ll 1 .}\right.$

The coefficient of isotropic diffusion is

$$
D=x\left(\lambda T_{e}+T_{l}\right) /\left(M_{l m}+\lambda m v_{e m}\right)
$$

If we neslect the influence of negative ions on the diffusion, we shall have $\lambda=1$ and the diffusion coefficient will be substantially underrated.

\section{**** THE EN D}

Novosibirsk Institute of Radio

Engineering and Communications
Received on 15 December 1964.
Contract No.NAS $-5-3760$

Consultants \& Designers, Inc. Arlington, Virginia
Translated by ANDRE I. BRICHANT on 13 September 1965

REFERENCES

[1]. - YA. I. AL'PERT. - Rasprostraneniye radiovoIn v ionosfore (Rad1owave Propagation in the Icnosphere).- Isd.AM SSSR, 1960.

[2]. - B.N. GERSHMAN. - Radiotekhnika i elektronika, 1, 720, 1956. V.P.Dokuchayev.IVUZ, Radiofizika, 3, 50, 1960.

[3]. - A.V. GUREVICH., ZhETF, 44, 1302, 1963. 
DISTRIBUTION

GODDARD SPACE F.C.

100 CLARK, TOWNSEND

110 STROUD

400 BOURDFAU

600 PIEPER

610 MEREDITH

SEDDON

611 McDOMALD [3]

DAVIS

GUSS

KNIFFEN

ABRAHAM

BOLDT

612 HEPPNER

NESS

613 KUPPERIAN

614 LINDSAY

WHITE

615 BAUER

A IKIN GOLDBERG

STONE

SIRBU

640 HESS

INTAD

MAEDA

HARRIS

SPEISER

STERN

630 GI for SS

620 SPENCER

NEWTON

252 LIBRARY

256 FREAS

[3]

[5]
NASA HQS

SS NEWELL, NAUGLE

SG MITCEEIL

SCHARDT

OPP

SCHMERLING

DUBIN

SL LIDDEL

FELLOWS

HIPSHER

HOROWITZ

SM FOSTER

ALIENBY

GILI

BADGLEY

RR KURZWEG

RV-1 PEARSON

RRP GESSOW

RTR NEIIL

ATSS SCEWIND

ROBBINS

WX STEET
OTHER CENTHE:

AMES

SONETT [5]

IIBRARY [3]

IANGLEY

160 ADAMSON

HESS

185 WEATHERWAX [?]

JP L

SNYDER

BARTH

UCIA

COLEMAN

UC BERKELEY

[4] WIICOX 